ISSN 1112-9867

Available online at

http://www.jfas.info

\title{
INDIGENOUS ARCHITECTURE AS A CONTEXT-ORIENTED ARCHITECTURE, A LOOK AT INDIGENOUS ARCHITECTURE OF SHUSHTAR
}

\author{
A. Bahrami \\ Islamic Azad University, Central Tehran Branch
}

Published online: 05 June 2016

\begin{abstract}
What has become problematic as the achievement of international style and globalization of architecture during the time has been the purely technological look at architecture, and the architecture without belonging to a place. In recent decades, the topic of sustainable architecture and reconsidering indigenous architecture and what has existed before has emerged as a determinant principle to solve this problem. Because, the connection that architecture should make between natural environment, social conditions, economic conditions, etc. has skillfully been reflected in this type of design process. What is primarily important in this approach is context. Context is the background and environment in which architecture is shaped and contains both content and form, and Context-Orientation is an approach in which in addition to merely physical aspects, the human dimensions and cultural, social, and historical aspects are also gradually considered. In this respect, in such a design, the architect and urban planner should at first understand a place, context, and consider this parameter as the fundamental principle in his/her design process.
\end{abstract}

Author Correspondence, e-mail: bahrami.aidaa@gmail.com

doi: http://dx.doi.org/10.4314/jfas.8vi2s.52 
The present article is looking for explaining the role and place of context-orientation at the top of design programs, and by relying on the indigenous architecture of Shushtar, it is trying to explain how this approach has been emerged in the indigenous architecture, and to specify the importance of considering this topic in sustainable development.

Keywords: context-orientation; sustainable architecture; indigenous architecture; shushtar.

\section{INTRODUCTION}

Topics related to sustainability have become pervasive in a way that many feel that another word should be used for this purpose. Exactly for the same reason, many use the term ecologic. However, many others prefer using the statement of responsive to the environment. The words can be different, while the goals are always the same $\{1\}$.

Meanwhile, regarding the global environment as a context in which architecture finds entity is one of the very important and basic issues. Nowadays, the goal of environmental architecture is referred to the creation of sustainable and organized balance between nature, human, and artifacts. In general, those buildings are considered sustainable buildings that have had the least destroying impacts on the nearby created (artifact) and natural environments, their surrounding area, as well as their overall text and context. Hence, considering the design background and context in its different dimensions is considerable and fundamental principle in reaching sustainable architecture goals. In this opportunity we will identify context-oriented architecture and its emergence in the indigenous architecture.

\section{CONTEXT-ORIENTATION}

The meaning of context is the background and environment in which architecture is shaped and contains both content and form. Context-orientation is based on this principle that a phenomenon cannot be imagined abstract and separated from its surrounding, and the phenomena are not only in their monopoly of powers, essence and inner features, but they are also dependent on their environment and the collection of surrounding. Every phenomenon impacts on its surrounding environment and also is impacted from it, and they are interacting with each other. In fact, the entire universe is interconnected, and each component impacts on the whole, and any change in the component will leave an indispensable impact of itself on the entire universe. 
Schultz suggests the concepts of "meaning" and "structure" for understanding the spirit of place. The meaning of each object has its roots in its relations with other objects, meaning that in what the object gather together, an object is object due to its gathering. "Structure" instead, refers to the shape and form properties of a set of relations $\{2\}$.

\subsection{Dimensions of context-orientation}

Architecture is not a science separated from cultural, social, economic and sociological categories, and it actually is their reflection and resultant. The background and text in which the architectural work finds entity has exclusive physical, geographical, climatic, social, cultural, economic, historical, and etc. characteristics and features.

Merrill Guinness (1980) classifies context in the architecture under three general topics, form, activity, and climatic patterns. However, in this article the dimensions of context-orientation in 1Physical context, 2. Climatic context, 3. Socio-cultural context and 4.Historical context are investigated $\{14\}$.

\subsubsection{Physical context-orientation}

Elements like form and shape, scale, proportions, details of materials, texture, colors, geometry, accesses, orientation, landscapes and perspective, topography of place, vegetation cover statue, urban texture include density of buildings, streets and sidewalks and their proportion with each other, the link of old and new buildings, the sky line, the land line and the type of connection to the ground and many of these issues.

Thus, the realistic analysis and recognition of the design background in physical respect is an inevitable point. Some of these factors act in micro scale and some others act in macro scale. Undoubtedly, dealing with each one of the factors in its scale can be conclusive and effective. Although considering all these factors seems to be difficult, the existence of indigenous architectures of past generations as successful samples gives this promise that considering the environment and solving contemporary problems is not an unlikely and impossible point $\{5\}$.

\subsubsection{Climatic context-orientation}

Maintaining the god-given resources and respecting them, setting the environmental conditions by using natural energies and consuming the least fossil energy, and coexistence with the natural and climatic conditions are regarded as sustainable patterns in architecture and a step to reach sustainable architecture, and ultimately sustainable development. 
Regarding the climate of context and climatic factors in which we perform architecture can be a platform for flying towards sustainable architecture. Attention to this important issue opens the way to use natural powers such as sun, wind, water, etc. and minimizes the use of fossil resources.

As it was stated, by the aid of climatic recognition of architectural context and environmental capacities in the past, installation elements such as wind wards, windmills, mills, shvadans, pergolas, garden pits, cellars, and etc. were emerged.

Therefore, considering the climatic factors of region such as climatic characteristics of each context, wind, rain, changes in day and night temperature, air temperature, air flow, the sky statue, the sun radiation, etc. is essential $\{14\}$.

\subsubsection{Socio-cultural context-orientation}

The created changes in the human cultures and transformations in the community will always manifest their most important manifestation in the appearance of cities and urban buildings. Thus, architecture cannot be investigated as a separated science. Architecture cannot be observed as a science separated from categories of culture, sociology, politics, economics, psychology, and etc., because this excellent art has reached us hand to hand and chest to chest during the history by the capable hands of outstanding architects and scholars, and it has been the most beautiful manifestation and reflection of culture and tradition in each historical period. The originality and identity that is visible in every architectural work is in fact the spirit that its architect and builder gives to the lifeless body of a sculpture called building. Therefore, this is the designer who in addition to considering performance, technical, psychological, aesthetic issues, should also have a different look at premieres issues. Issues like culture, tradition, mysticism and philosophy, originality and identity of every land and the prominent human values should all be considered in the design of buildings and cities, and urban planning rules, so that our architecture and urbanism returns to its eternal development and glory $\{7\}$.

\subsubsection{Historical context-orientation}

If a community separates itself from the past, it has considered its human's effort useless, and discontinuing the historical continuation of human is the humiliation of his past life. We should take advantage of what past generations have done. If we want to progress in science, we must stand on the shoulders of pioneers. 
The context should also be viewed as a kind of history. The context should not be considered as a static factor and in a time, but it should be regarded as a dynamic, variable and flowing factor. The context of context-oriented architecture is itself in a way variable and moving. Every building which is built, is raised as a part of context, and as a part of context prepares context for its later. The history of context is about architectural buildings, the life history of architecture and urbanism $\{5\}$.

The historical evidences of architecture and urbanism indicate that architecture and urbanism in the past has been formed in balance with the environment. The traditional architecture has been formed with the trend toward ecological sustainability and society, with respect to and attention to natural resources and maintaining them for future generations. Regarding the indestructible energies like sun and wind and using them to improve thermal conditions of the biological space has been usual traditionally. Iranian traditional architecture is also one of the most admiring architectures in the creation of sustainable and suitable environment for living. Installation elements such as wind wards, shvadans, pergolas, garden pits, cellars, and etc. along with accurate architectural principles and the proportion of constructions with the environmental and climatic conditions, and ecological capacities all are the proofs on this claim.

\section{CONTEXT-ORIENTATION IN ARCHITECTURE}

Hegel, Herder, Arnold Toynbee and Marx mentioning the relationship between human and his environment, have distinguished the importance of natural environment. But they have simultaneously emphasized on the ability of human to respond and form the world. It is obvious that human makes not only the nature, but also himself, community, and culture. One of the principles of Marxism is that human as a biological entity is a part of nature, and the place he builds manifests his understanding about its environment that completes it, and symbolizes it $\{2\}$. On this basis, the context-orientation architecture emphasizes on the necessity of considering the environment surrounding the work, and believes that the balance between architecture and environment can be an effective and strengthening factor both for the work itself and for the context of work. Context-orientation is a pattern to create more desirable environment. Thus more recognition and awareness and a deeper understanding about the context and environment is an essential and inevitable issue for designers and architects. 
Context-orientation is a viewpoint that considers specific characteristics of a place and implementing them in the contemporary design. "Context-oriented architecture is an effort to show the power of visual favorable environment on a more macro scale of architecture; the message of context-oriented architecture is to consider the physical environment surrounding the architectural work" $\{3\}$.

The designer and architect should understand the message of context and the background of design and text, and then design with regard to the existing conditions. The design should be based on the realistic attitude to the information of environment, and it is required that in his view the architecture and the bilateral interaction context are the founder of architecture. Interaction with context neither means abolition and elimination of text, nor means contradicting and struggling with it. Thus, our definition about context-oriented architecture is the architecture which results in the creation of more desirable and more excellent works in the balance of environment. Architecture, "while implicitly considers spatial differentiation, explicitly demands the continuation of physical and non-physical values of existing place and context. However, it does not negate the creation of new values; the major approach of context-orientation is to understand context values and to continue them in future".

\subsection{Sustainable architecture}

According to the intellectual theory of international style in the modern architecture, the building should lack any regional, city, neighborhood, and climatic characteristics. Modernists knew the architecture as a technologic issue. Technology has a general property, and follows the same principles and rules all over the world. The experience of modern art and architecture or international style which was to disconnect the relationship between the environment of history and tradition is an obvious sign of a failed experience.

Robert Venturi, the American post-modern architect in 1996 undermined the principles of ideas and ideology of modern architecture. He called attention to the human characteristics and human oriented architecture. Venturi does not have any belief in international style, and instead he believes on context-orientation, meaning that every building should be designed and implemented according to cultural, social, historical, physical contexts and the conditions of that site and building. According to post-modernists the following conditions determine the building form: 
1. The cultural, social, historical, and economic characteristics of people who use the building.

2. The characteristics of city, street, square, lane, and shop.

3. The climatic, humidity, cold, heat, forest, and desert conditions.

4. The method of daily life of the inhabitants of building, their needs, and their intellectual pre-contexts in relation to the biological forms.

Post-modernists have a cultural attitude towards architecture, and culture is different from one region to another. Another word, the post-modern architects want to change the view of architects towards the history, culture, tradition, and in short what forms the human identity and physical environment surrounding it $\{4\}$.

"Through building, man-made places are created that have the soul of their own special place. The soul of man-made place, in the indigenous architecture should be well responsive to its natural place" $\{4\}$.

The recent trend in the architecture emphasizes on conscious designing of the environment. The buildings that ignore the environment surrounding their own, and exclusively use natural resources to provide comfort, not only loss and damage the environment and the area around themselves, but also have a deep impact on the whole ecosystem. The continuity of building with its location, community, and the surrounding region makes the building to connect more with its context and it can increase the ratio of energy productivity in the building by successful interaction with the environment.

Finally, the context-oriented sustainable architecture is a kind of approximating to the product of design that has maximized taking advantage of the internal properties of background and environmental conditions, while leading the undesirable conditions resulted from this construction to minimum. Context-oriented architecture emphasizes on the ground orientation and linking the environment with the space, and it is shaped by understanding the message of its background, and in fact realizes and designs the message that the background of architecture has transferred to it; hence the building will be a small component of the surrounding nature.

\section{THE SCALE OF CONTEXT-ORIENTATION}

Context-orientation is raised in various scales and levels. In the micro scale, it starts from the building itself, site, the ground in which the building is located, and then it is raised in the 
neighborhood and quarter. In this stage, the context-orientation architecture moves from the pure architecture to urbanism. In the greater scale, in the environment of city it deals with district, area, followed by areas around the city and suburban areas.

Context-orientation is not limited to this level either. It can go beyond one building to the neighborhood, area, regionalism, and this stage, and it finds a global dimension. Therefore, context-orientation can expand its dimensions in the range of Earth Planet.

In a general sense, it can be said that the beginning of context-orientation is neighborhood, but context-orientation expands in two micro and macro directions. Context-orientation in the macro scale deals with regionalism, and in micro scale deals with the internal atmosphere of building. But the global aspect of regionalism also goes beyond region limit and finds global dimension. In this way, although context-oriented architecture plunges itself deeply "in place", it raises its "presence" to far away, to the cities, countries, world and the universe $\{5\}$.

Adrian Smith and Gordon Gill who believe in sustainable architecture at international level say: the building design should be rooted from its role in the regional, district, and global context. In the text of global development, and when all cities are designed and created to damage the environment, these environmental goals are not only achievable, but they are also essential and indispensable for survival.

\section{INDIGENOUS ARCHITECTURE}

Indigenous or land architecture can be said to any kind of architecture belonging to a specific place. This can include the architecture of simple rural-urban buildings to great buildings and even memorial monuments, and in most cases the indigenous architecture has been mistakenly regarded equal to the rural architecture.

Indigenous architecture, as it is obvious from its name, is like the flag representing the architecture of each region, and it is the art of making and decorating the building with regard to the cultural beliefs, customs and traditions, identity and climate, and in another dimension means the architecture in harmony with the nature and environment which includes architecture and nature besides each other while maintaining the comfort of inhabitants, and it is the greatest achievement of human in manufacturing artifacts, and carries basics such as: maintaining the life cycle (design, construction, maintenance, demolition, returning to the environment, and reuse), optimization use of sustainable resources and the environment (natural resources and materials), 
the environmental understanding and their reflection in the building (culture, customs and tradition, and religion). It is completely obvious that every climate of Iran has the specific indigenous architecture of its own and to understand its basics, knowing the types of climate and investigating constructions in them is necessary $\{8\}$.

It is about half a century that the indigenous architecture has been raised as a part of the theoretical topics and a component of empirical researches of architecture. This topic at first was called as different names such as unknown architecture, traditional architecture, people architecture and folk architecture or even as architecture without architect. Although this architecture has historically been subject to various phenomena, it has been able to maintain its special identity. Since ecology is regarded as the valid certificate of the people of a land, and represents their customs and traditions, spirit and feelings, thought and belief, taste, preference and art, in the formation of indigenous architecture, some of the social and economic relationships are skillfully reflected in the natural environment and cultural symbols. The indigenous architecture which is realized far from professions has the responsibility of responding the requirements of a community in connection with natural factors and humans' spiritual demands. Because, it is born in the planning and implementation by their participation, and it is inspired from their daily life, and it is established far from showing off and external decoration. Thus, the indigenous architecture, without having style and far from specific form and model has maintained the characteristic of improvisation. For this reason, we find the indigenous architecture and artifacts in the mysterious link, familiar, and understandable in confrontation with unknown lands $\{9\}$.

\section{INDIGENOUS ARCHITECTURE OF SHUSHTAR}

In the structure of the city of Shushtar like many other cities, some characteristics are observed that understanding them puts a clear image of this texture in front of our eyes. In this article, the meaning of indigenous architecture is the architecture other than the contemporary architecture of the city of Shushtar that in respect of the concept and representation of a context-oriented and sustainable architecture has never followed its past and indigenous architecture. The old urban texture of Shushtar has been designed by having impacted from factors like natural environment, weather, urban needs, the need for security of city against the invasion of aliens, and it generally has introspective architecture. General architecture spaces and historical monuments have been 
located in a dense combination connected and beside each other. The design of city has been in a way that the residential space, without having difficulty in respect of application, has been located beside urban elements such as grand mosque, market, school, and bath.

\subsection{Relationship with natural background}

Shushtar has a specific and unique relationship with its natural environment. The design governing on the texture of Shushtar is a free, natural, and organic way that is manifested in its street and houses layout. In general, it seems that the form and shape of city depends sometimes on the composition and shape of land, sometimes on the rocks, and sometimes on the river, that in this way a specific and coordinated relationship has been created with the natural elements.

Spaces as Kat are among other achievements of architecture, when facing the river landscape. These spaces have been created on the rocks in the river wall for recreation and can be used as perspective, and in some cases have connection from Shvadans of riverside houses to dedicated Kats. Such landscapes are also seen in the houses that in spite of having different form have the same application. Moreover, no building can be found in the riverside that ignores the existing background and landscape $\{10\}$. In the architecture of residential units the relationship with the natural background is also obviously visible. The architecture of Mostofi's house is introspective architecture type with the central courtyard pattern, located at a distance of 50 meters from Shatit River. Living spaces (rooms) around a central courtyard are looking inward and in the edge of complex facing the river we observe a semi-open space with the application of public space. In fact, the view to the river has been framed on the west side of the central courtyard, and has been brought inside the central courtyard. The goal of architect might be that the residents of house benefit one by one of the spaces equally from the central courtyard and also from the view and landscape of river equally.

In another example of the indigenous architecture of Shushtar we reach the Marashi's house at Gargar riverbank. In this house we will observe the attention of designer to the view and landscape of natural potentialities of place in the complex design. The special natural facilities in different situations in respect of positioning of complex have changed the usual pattern of central courtyard of old houses of Shushtar in some cases and has brought the nature inside the complex. The northern courtyard of Marashi's house is a place that we see the dedication of nature, namely waterfalls for this house. 


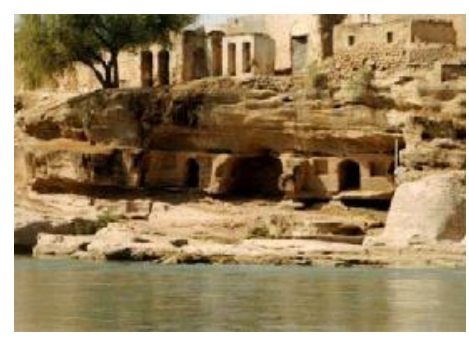

Fig.1. A Sample of Kat on the Edge of Karon River

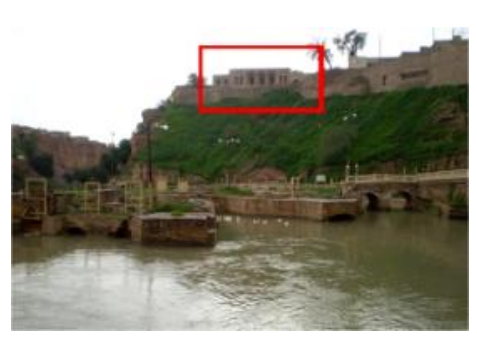

Fig.2. The Porch Facing

Karoon River in Mostofi's

House

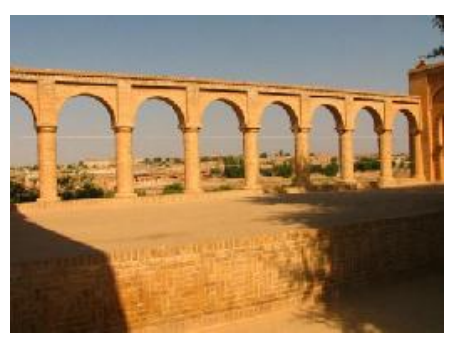

Fig.3. The Porch Facing

Gargar River in Marashi's

House

\subsection{Materials and details}

The most important characteristics of such communities are the form, material or texture, color of surfaces and details of residential unit. The size, shape and location of gaps in the wall and roof ventilation tube represent the need for light, ventilation, movement of humans and animals and goods. The space of living rooms has small orifices that were primarily created for air ventilation. The size of door corresponds with its use, meaning that if the animals or large carts are the properties of house, the entrance is considered larger. The door, when opened, more lights enter into the house, and the same door, when the air is favorable, is also used as the air ventilation. Preserving the privacy of house is also created through a porch or a railing in front of the entrance. The form and texture of roofs are also completely clear, and are among the important elements in the appearance of building.

Choosing the material of wall and its color has direct relationship with the climatic conditions. The color of inside space is usually white or another light color to reflect the limited ratio of light that enters from small orifices of external walls to the room, and provide more light for the room. To decorate the external appearance, the brickwork is used to create geometric shapes $\{11\}$. 


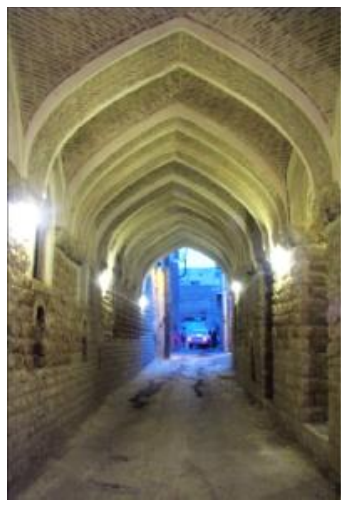

Fig.4. Sabati in Shushtar

\subsection{Negative spaces}

Narrow paths, alleys, bridges and roofed routes of pedestrians (Sabats) that exist between houses relate residential units and create the direction to neighborhood centers, market, and the important elements of landscape.

One of the major applications of Sabat is to offer shadow and a cool space for the pedestrians who have taken refuge to it after crossing the long alleys, especially in the annoying and cumbersome heat of the Shushtar. The temperature of space beneath the Sabat both in summer and in winter is always desirable, in a way that in summer the difference of temperature between the inside and outside of Sabat creates air current and also causing more cooling air inside the Sabat compared to its outside. But in winter, since the space inside Sabat is more restricted compared to the outside, the air inside is warmer than its outside environment.

One of the most important functions of Sabat is to create integration and strength in the adjoining houses, in a way that this element helps the building to withstand the forces applied on it. In addition to physical functions, Sabat has other functions too that are regarded much more important than the first type, and they are cultural and social functions $\{11\}$.

\subsection{Urban spectacular monuments}

In the general plan of the city of Shushtar, the urban spectacular monuments manifest in the streets domain or focus points of view. Since the social life in this city is particularly based on religion of Islam, these types of buildings in all cases are mosque or shrine. The simplest type of 
these buildings follow the same principles of residential houses, but to separate them from the houses, this type of buildings has a roof from outside with a specified design.

Most of the time the external form of these exceptional buildings shows the activities inside them that eliminates the monotony in the city that is due to similar residential houses. The greater mosques have a more outstanding position and occupy major squares and are visible from any entry point to the city $\{11\}$.

\subsection{Spatial organization of residential units, in coordination with the climate and culture}

Among the first factors which are visible in investigating and studying the spatial organization of residential units in the old texture of Shushtar is the breadth and diversity of relevant performances. House in the old Shushtar on the one hand is the status and habitat of the patriarchal extended family which is practically the greatest social unit that live in Iranian feudal city in security and peace around a center of gathering, and on the other hand accommodate the vast majority of the areas of living, working, and family's activity with its own, and hence it can be considered as the first, the most integrated, and the most real module in human gatherings hierarchy $\{12\}$.

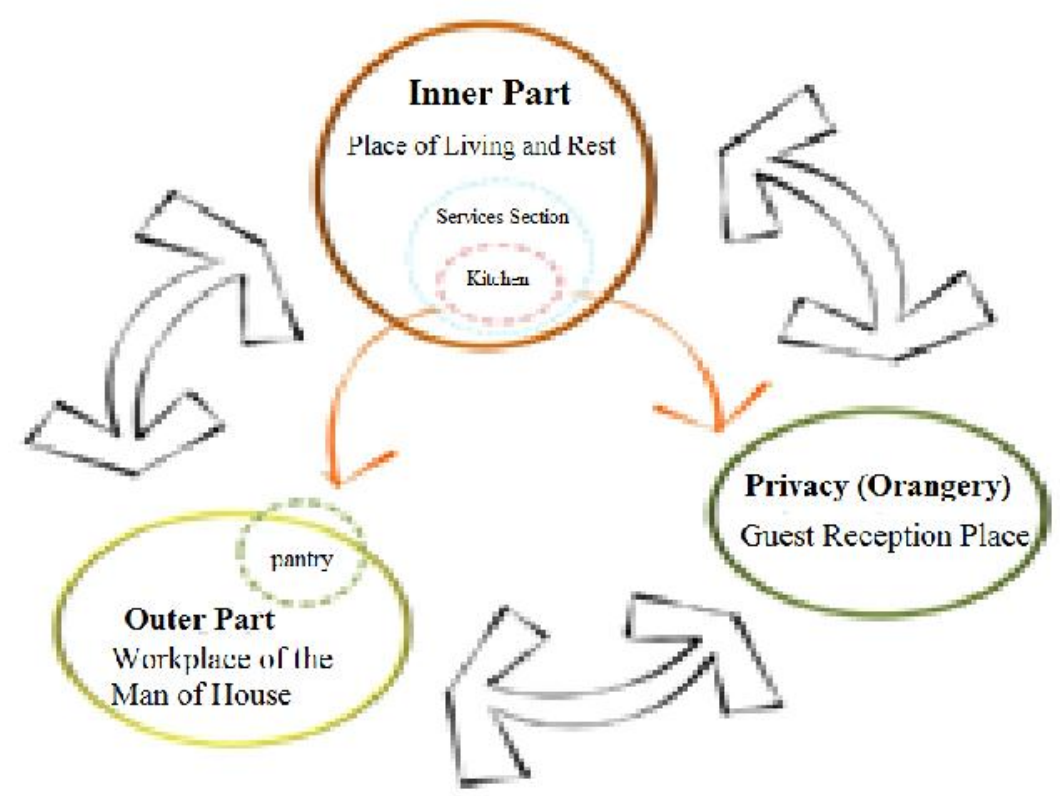

Fig.5. Space Composing Residential Unit in Safavid Era 
Another important factor that is considered in investigating residential buildings of Shushtar is the diversity of constructive elements of building in physical respect. The oldest residential building in the old Shushtar belonging to the Safavid era was composed of three parts of inner, outer and privacy. The outer was the workplace and secretariat, the inner was the place of living and rest, and the privacy was the place of receiving the guests and people who entered the city from other regions for transaction and meeting with the man of the house. The service section including the unit of kitchen and pantry was designed for providing the needs of various parts in connection with the three major parts of unit $\{13\}$.

In the Safavid era by decomposition of primary families, the diversity of living areas in the residential unit was gradually decreased, so that in the houses remained from the Qajar era that compose the greatest part of the old houses of Shushtar, from the privacy section that in the Safavid era was considered as the major element of housing, no effect is at least independently evident. The summarization process of spaces and increasing the concentration and density of residential units continued in the Qajar era, and some changes emerged in the distribution pattern of inner and outer parts, and in many cases the outer part which was previously based beside the inner part as an independent courtyard was transferred to the upper section of inner part with or without independent courtyard. The continuation of aforementioned process has resulted in the emergence of one of the most important quantitative and qualitative confrontation fields of the architecture of residential buildings in the old Shushtar against today's situation, that for example the breakdown of patriarchal family structure and the change of housing to the place of independent family can be mentioned, that in most cases, except residence, which is solely the residence of mononuclear family, does not perform any other function. 


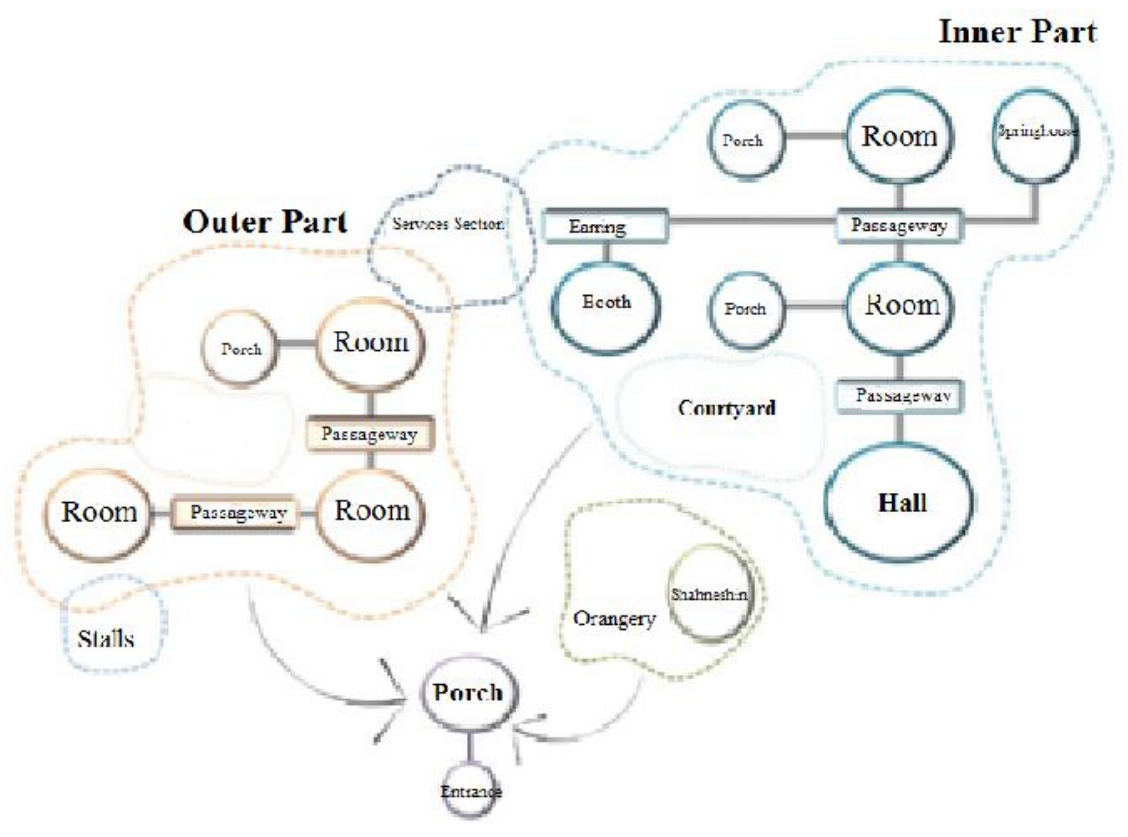

Fig.6. Spatial Diagram of a Residential Unit in Shushtar in Safavid and Qajar Eras

The concentrated structure of residential unit around the central courtyards has exposed the inner image of buildings in sight without any obstacle. The vertical stone or brick piers raised from wall level along with prominent horizontal lines divide the facade surface into numerous parts, that each one of them is perfect by itself. The design of residential unit has been created with ultimate precision. All internal and external spaces are simple and economic. No space is wasted, and they are used accurately, the type of buildings depends on the existing materials, the form and shape of buildings are the major element of the appearance of city. Most of these houses have a flat roof to be used as a greater space for work, recreation, sleeping, drying food and clothing and maintaining home appliances $\{11\}$.

\subsection{Indigenous architecture of shushtar and compatibility with climate}

The heat factor is regarded as the most important and effective factor in the formation of residential buildings in Shushtar. Shvadan as cellar space in the underground, wall thickness in the form of a thermal insulation, Khovon as a solution for creating shadow on the walls of building, are all effective elements against heat factor and the creator of residential complexes in Shushtar $\{13\}$. 
The indigenous architecture of this region that has the best compatibility with its climatic conditions has the following characteristics:

- Creating air current by numerous open spaces in the major parts of residential unit.

- Creating air circulation in various parts through temperature variation between cold air due to sufficient shadow and warm air by using small and highly shadowed courtyards.

- Creating shadow on the roofs and walls through difference of numerous volumes and construction of wooded walls, and making the walls non-flat by different forms of wall building.

- The buildings are relatively condensed and are built in one or two floors to minimize the exchange of heat through sidewall of building.

- The buildings have small and deep central courtyards (with elevated walls) to provide the utmost shadow. Water pond and green space are not ineffective in the air moderation of these courtyards.

- Creating summer and winter settlement spaces, around the central courtyard like other parts of Iran is common, and provides the conditions of seasonal use of four heads buildings.

- In these regions, using underground that creates a cool space during the summer is also common. In some regions like Dezful and Shushtar that the ground has good resistance, the undergrounds have been built very deep and in two or more floors that are known as Bedchamber (shallower underground) and Shvadan (deeper underground). In shvadan that even its dept reaches sometimes to more than ten meters, the air is very cool and they are regarded as assured shelters at the exhausting noon of summer.

- In these regions, the materials of walls and the roof of building are bricks which are regarded as heavy materials with high heat capacity. The roofs have arch that create more shadow on the roof, and also increase the internal height of rooms.

- In some cases, in order to use the roof the arched roofs are flatted and high grid bumps are used for the turret of roof that while creating shadow on the roof lets the air current to pass through the roof surface. Thus, the heated air on the roof is taken by the wind and also the pleasant cool air is provided for the users of the roof in the hot nights. 
- Using roofed porches around the courtyard and in front of the rooms on the one hand provides required shadow, and on the other hand provides a suitable semi-open space for using in the days that the weather is not very hot.

- Using small windows to prevent the penetration of heat into the building is essential. Instead, in order to establish air current, the trapdoors or small orifices at the top and bottom of openings are used.

\subsection{Representation of socio-cultural relationships in urban body and architecture of shushtar}

Considering that the religion of Islam has spread shade on the individual and social relationships of the inhabitants of this city, we also witness the presence and representation of this type of culture and ideology in overall organizing of urban space and residential units. The urban spectacular monuments have allocated the buildings like mosque and shrine to themselves and undertake the social life of city beside the market of city to the extent that at the days of holding religious ceremonies, the places of citizens' gathering are the same religious places. In respect of spatial organizing of residential units, privacy and adherence to the principles is one of the basic principles of formation of these units. As it was said before, the introspective and concentrated architecture of houses along with internal divisions of these places named as inner, outer, and service spaces is itself the proof on this claim. The integration of working and living spaces in some cases indicate the livelihood of inhabitants of house and its representation in the body of residential unit. The harmony and coordination with the culture and social relations and citizenship temper is an issue that we clearly observe in the urban and neighborhood organizing and hierarchy. The urban body has been shaped by neighborhoods, and each neighborhood has had its specific features and tempers, and those who settle in a neighborhood were close to each other in cultural and intellectual respect, what is missing in contemporary urban neighborhoods.

\section{CONCLUSION}

Recently many methods of environmental technologies, due to the inability of their designers who could not specify the continuity and socio-cultural content of the context of architecture, or could not understand the needs and expectations of those who want to use it, before being completed successfully, encounter failure. Actually, here the talk is about forgetfulness that how 
the culture and local values should be preserved. This issue in fact impacts on the success or failure of a project. Nowadays we are observing the presence of architecture and urbanism without identity and belonging to a place. The architecture occurring in the north of country is extremely similar or equal in physical and application respect with the architecture, for example in the warm climate existing in Khozestan. Today, with regard to the population growth and the need for housing, what has met the needs of a nation is unfounded and anonymous housing and towns appeared not only in its spiritual and identity dimension, but also it in the shaky and unstable structures. A form of architecture that should be replaced by the existing situation is a type coordinated with cultural, social, environmental, climatic, and economic criteria; otherwise the same wrong response should pay a heavy cost for reconstruction and the return of missed values. Such an architecture and urbanism relying on its background during the time with regard to its sustainability will meet the present and future requirements of its users. By learning and modeling from Iran's indigenous architecture, and the sample mentioned in this article, Shushtar architecture, we witness the designs with logical goals in line with preserving existing energies and a very cohesive coexistence with the surrounding and natural environment for a long living without the need for nonrenewable energies. The result of this process is a type of sustainable architecture in connection with the environment and the continuation of physical and nonphysical values of context and background in which architecture is manifested. In such architecture, regarding the physical, climatic, cultural, social, and historical contexts and background of architecture, and understanding the surrounding environment and the point that that is the same as this, are among the important principles in its sustainability.

\section{REFERENCES}

[1] Charles C. Cosmic Jump Architecture, Translation: Vahid Qobadian and Dariush Satarzadeh, Publication of Islamic Azad University, Tabriz Branch., 2008.

[2] Schulz N. The Place Spirit towards the Phenomenology of Architecture, Translaion: Mohammad Reza Shirazi, Publication of Rokhdad Noo, Tehran., 2009.

[3] Brolin B.C. Context-Orientation Architecture, Adaptation of New and Old Buildings, Translation: Razieh Rezazadeh, Publication of Khak, Isfahan., 2004.

[4] Qobadian V. Principles and Concepts in Contemporary West Architecture, The Cultural Research Office, Fifth Edition, Tehran., 2006. 
[5] Shirazi M. Context-Orientation and Regionalism in Architecture, Monthly Magazine of Infrastructures Engineering., 2009, First Year, 8, 2009.

[6] Ahmadi Z. Context-Orientation and Sustainable Architecture, The Proceedings of the First National Conference on Sustainable Architecture, Hamedan, March 2009.

[7] Ghasri M.A, Khosravi M. Iranian Culture in the Mirror of Architecture and Urbanism.

[8] Soflaee, Farzaneh. The Sustainability of Climatic Elements in Traditional Iranian Architecture", Third Conference on Optimization of Fuel Consumption of the Building, 2003.

[9] Khodabakhshi, Shohreh, Mofidi, Majid. Sustainable Construction in Connection with Traditional Iranian Architecture, Third Conference on National Energy, 2001.

[10]Persian Design and Manufacture, Consulting Engineers. A Comprehensive Conservation Plan of the Historical Context of Shushtar, The Ministry of Housing and Urban Development, Tehran, 2009.

[11]Daz, Consulting Engineers. Master Plan for the City of Shushtar, The Ministry of Housing and Urban Development, Tehran, 1977.

[12]Zista, Consulting Engineers. Report on the Plan and Design of the Revival of the Old Context of Shushtar, The Ministry of Housing and Urban Development, Tehran, 1992.

[13] Rahimieh, Farangis, Robobi, Mostafa. Recognition of City and Indigenous Housing in Iran, the Semi-Humid and Warm Climate, Dezful and Shushtar, The Students Association of the University of Tehran, Tehran, 1974.

[14] Ahmadi Z. Context-Orientation and Sustainable Architecture, Proceedings of the First National Conference on Sustainable Architecture, Tehran, 2009.

\section{How to cite this article:}

Bahrami A. Indigenous architecture as a context-oriented architecture, a look at indigenous architecture of Shushtar. J. Fundam. Appl. Sci., 2016, 8(2S), 380-398. 